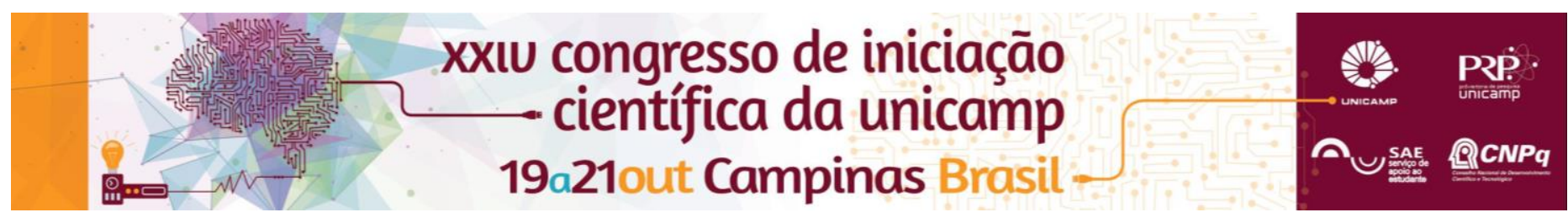

\title{
UTERINE RESIDUAL DISEASE AFTER CONIZATION IN WOMEN TREATED FOR MICROINVASIVE CARCINOMA OF THE CERVIX - EVALUATION OF 607 CASES
}

\author{
Ana Carolina M. Silva*, Caio A. Hartman, Julio C. Teixeira, Joana F. Bragança.
}

\begin{abstract}
Objective: to assess the prevalence of residual disease in hysterectomy specimens after conization in women treated for squamous microinvasive carcinoma of the uterine cervix (MIC). A cohort of 607 patients with MIC diagnosed and treated at Campinas State University, Brazil was analyzed. All patients underwent cervical conization and of these, 388 followed by hysterectomy. Residual carcinoma / CIS in the hysterectomy was highly associated with positive endocervical conization margins $(p<0,0001)$, in 171 cases of free conization endocervical margins, 32/171 $(18.7 \%)$ had residual disease: $20 \mathrm{CIS}(11.7 \%)$, and $12 \mathrm{MIC}(7 \%)$.Positive endocervical margins are highly associated with residual disease in hysterectomy specimen $(61.1 \%)$ so further treatment is mandatory. Conservative treatment should be carefully evaluated.
\end{abstract}

Key words: microinvasive cervical cancer; residual disease, surgical treatment

\section{Introduction}

According to the latest revised FIGO staging from 2009, stage IA or microinvasive cervical carcinoma (MIC) are lesions up to $5 \mathrm{~mm}$ in depth and $7 \mathrm{~mm}$ in width and divided into stage IA1 (depth of invasion $\leq 3 \mathrm{~mm}$, width of lesion $\leq 7 \mathrm{~mm}$ ) and stage IA2 (depth of invasion $>3 \mathrm{~mm}$ and $\leq 5 \mathrm{~mm}$, and width $\leq 7 \mathrm{~mm}$ ). The diagnosis of MIC should be based on analysis of cervix conization specimens [1]. Management of patients with MIC varied from cervix conization to radical hysterectomy $(\mathrm{RH})$ with or without lymphadenectomy [2]. Stage IA1 MIC is traditionally treated with a simple hysterectomy $(\mathrm{SH})$ and conization for young patients who have desire for fertility. Although it has been suggested by several retrospective studies that MIC has excellent prognosis and less radical surgery could be considered for these cases, data regarding the risk and extent of residual disease in these settings are no uniform at this time [3]. The aim of this study is to assess the prevalence of residual disease in hysterectomy specimens after conization in women treated for squamous microinvasive carcinoma of the uterine cervix.

\section{Results and Discussion}

A cohort of 607 patients with MIC diagnosed and treated at Campinas State University, Brazil was analyzed. All patients underwent cervical conization and of these, 388 followed by hysterectomy. Endocervical margin status of the cervical conization and the presence of residual disease in the hysterectomy specimens were analyzed. 211 of 388 conization specimens had positive endocervical margins (CIS=192/ $M I C=19), 171$ were negative and 6 had non evaluable margins. In hysterectomy specimens 161 cases had residual disease (CIS or MIC) and 221 were free. In 192 conization specimens with endocervical margins positive for CIS, 73 (38\%) had CIS, $45 \mathrm{MIC}(23.4 \%)$ and 74 (38.5\%) no residual disease in hysterectomy specimen. In the 19 conization margin positive for MIC: 5 had CIS (26.3\%), 6 had MIC (31.6\%) and 8 no residual disease (42.1\%). Residual carcinoma / CIS in the hysterectomy is highly associated with positive endocervical conization margins $(p<0,0001)$. On the other hand, in 171 cases of free conization endocervical margins, 32/171 (18.7\%) had residual disease: $20 \mathrm{CIS}$ (11.7\%), and $12 \mathrm{MIC}$.

Chart 1. Prevalence of uterine residual disease according to conization margins

\begin{tabular}{cccc}
\hline RESIDUAL HYSTERECTOMY DISEASE & YES & NO & $\mathbf{p}$ \\
\hline POSITIVE ENDOCERVICAL MARGIN & 129 & 82 & $<0,0001$ \\
\hline NEGATIVE ENDOCERVICAL MARGIN & 32 & 139 & ref \\
\hline TOTAL & 161 & 221 & $382^{\star}$ \\
\hline
\end{tabular}

* 6 cases had non evaluable margins.

\section{Conclusions}

Positive endocervical margins are highly associated with residual disease in hysterectomy specimen $(61.1 \%)$ so further treatment is mandatory. Conservative treatment should be carefully evaluated, and close follow up should be done even in patients with free conization margins because almost $20 \%$ of the patients had residual disease in hysterectomy specimen.

\section{Acknowledgement}

Acknowledgment to CNPq for fterunding and support.

\footnotetext{
1 Pecorelli S, Zigliani L, Odicino F. Special Communication. Revised FIGO staging for carcinoma of the cervix. Int J Gynaecol Obstet. 2009;105:107-8.

2 NCCN Clinical Practice Guidelines in Oncology. Cervical Cancer https://www.nccn.org/professionals/physician_gls/pdf/cervical.pdf [accessed 02.07.16].

3 Park JY, Lee SM, Yoo CW, Kang S, Park SY, Seo SS. Risk factors predicting residual disease in subsequent hysterectomy following conization for cervical intraepithelial neoplasia (CIN) III and microinvasive cervical cancer. Gynecol Oncol. 2007;107:39-44.
} 